\title{
Effect of Polypropylene and Polyvinyl Chloride Plastic Film Packaging Materials on the Quality of 'Yalova Charleston' Pepper (Capsicum annuum L.) during Storage
}

\author{
Bulent AKBUDAK ${ }^{*}$ \\ Department of Horticulture, Faculty of Agriculture, University of Uludag, Gorukle Campus, 16059 Bursa, Turkey
}

Received February 26, 2007; Accepted August 3, 2007

The long pepper (Capsicum annuum L. cv. 'Yalova Charleston') was stored in plastic film with various oxygen $\left(\mathrm{O}_{2}\right)$ and carbon dioxide $\left(\mathrm{CO}_{2}\right)$ permeabilities consisting of $7 \pm 1^{\circ} \mathrm{C}$ temperature and $90 \pm 5 \%$ relative humidity (RH). Physico-chemical changes were recorded on 0, 10, 20 and 30 days of storage. Weight loss was higher in pepper stored under normal atmosphere (NA) compared to modified atmosphere packaging (MAP). Initial total soluble solids of $4.20 \%$ increased to $5.27 \%$ in NA. The acidity and ascorbic acid contents of peppers decreased during storage. The highest values were recorded at the end of storage from the fruit stored under PP (polypropylene). Changes in fruit color at the end of storage proceeded more slowly in the treated fruit. Total chlorophyll values exhibited significant decline in the fruits subjected to NA. However, the chlorophyll content in the fruits subjected to PP was low. The color values obtained from fruits supported the chlorophyll findings. At the end of the study, 35 $\boldsymbol{\mu}$ PP packaging material gave the best result at the end of $\mathbf{3 0}$ day-storage with respect to the parameters evaluated in the study. Therefore, especially $35 \mu$ PP treatment was effective with regard to delaying the maturity along the storage and fruit quality in peppers.

Keywords: Capsicum annuum, modified atmosphere, postharvest cold storage, quality parameters

\section{Introduction}

Food marketplace with the new products and changing trends, and fresh-cut produce remains at the top of the list of products meeting the needs of busy consumers. The value of fresh-cut produce lies in the primary characteristics of freshness and convenience. Food safety, nutrition and sensory quality are required while providing extended shelf-life and freshness. However, physical damage during preparation of minimally processed products causes an increase in respiration rates, biochemical changes and microbial spoilage, which may result in degradation of color, texture and flavor of the produce (Gonzalez-Aguilar et al., 2004).

In recent years, a number of new food processing and packaging technologies have been applied to fresh produce by the food industry. Modified atmosphere packaging (MAP) has been successful in maintain quality of fruits and vegetables. Moreover, packaging and low temperature storage has been shown to increase shelf life by slowing the

*To whom correspondence should be addressed.

E-mail: bakbudak@uludag.edu.tr growth of spoilage organisms (Hussein et al., 2000). MAP has been used to prevent or retard postharvest fruit ripening and associated to biochemical and physiological changes by favorably altering the $\mathrm{O}_{2}$ and $\mathrm{CO}_{2}$ levels around the products (Gonzalez-Aguilar et al., 2004, Gonzalez-Aguilar et al., 1998, Morales-Castro et al., 2002, Qi et al., 1999). Therefore, the primary purpose of the present study is to prolong the storage period of pepper fruits by alternative storage techniques (MAP), and to investigate their effects on weight loss, total soluble solids (TSS), titratable acidity (TA), ascorbic acid, fruit color, total chlorophyll, the ratio of $\mathrm{O}_{2}, \mathrm{CO}_{2}$ and ethylene $\left(\mathrm{C}_{2} \mathrm{H}_{4}\right)$ content and overall appearance during storage.

\section{Materials and Methods}

Plant materials, growth medium and growth conditions The study was conducted during the 2004-2005 growing season at the Uludag University, Research and Training Greenhouse (glasshouses with automatically temperature and humidity control). Seedlings produced from surface disinfected seeds (with a $60 \%$ solution of commercial bleach for $10 \mathrm{~min}$ 
and rinsed four times with distilled water) were grown from 5 January to 15 May in $1.5 \mathrm{~L}$ capacity pots (one seedling per pot) containing soil and sand mixture (soil : sand, 75:25, v/v). Growing conditions consisted of a day/night temperature regime of $22 \pm 2 / 18 \pm 2{ }^{\circ} \mathrm{C}$ and $16 \mathrm{~h}$ photoperiod. Plants were watered as needed and fertilized weekly with N-P-K formulations were 15-15-15.

Fruit material The pepper cultivar 'Yalova Charleston' (Capsicum annuum L.) (yellow-green color, thick fruit wall, sweet, charleston type pepper) which are intensively grown under protected cultivation in Turkey was used in the trial (Anonymous, 2003). Fruits of the same size, shape and injury free were selected for the experiment.

Treatments Five hundred grams pepper cultivars were enclosed in plastic film packages $(25 \times 30 \mathrm{~cm})$ and sealed by a Petra FS 500 plastic covering machine. The permeabilities of the plastic film packages were determined in the Scientific and Technical Research Council of Turkey in Gebze county, Turkey. MAP studies were carried out by using $35 \mu$ PP (polypropylene) with $\mathrm{O}_{2}$ permeability of $431.10 \mathrm{~mL} / \mathrm{m}^{2}$ day atm at $7^{\circ} \mathrm{C}$, and $\mathrm{CO}_{2}$ permeability of $1381.50 \mathrm{~mL} / \mathrm{m}^{2}$ day atm at $7{ }^{\circ} \mathrm{C}$ and by using with $35 \mu$ PVC (polyvinyl chloride) $\mathrm{O}_{2}$ permeability of $62.70 \mathrm{~mL} / \mathrm{m}^{2}$ day atm at $7{ }^{\circ} \mathrm{C}$, and $\mathrm{CO}_{2}$ permeability of $35.90 \mathrm{~mL} / \mathrm{m}^{2}$ day atm at $7{ }^{\circ} \mathrm{C}$. All treatments in normal (NA) and MAP were stored in $7{ }^{\circ} \mathrm{C}$ and $90 \pm 5 \%$ RH.

Quality parameters Parameters such as weight loss (\%), TSS (\%), TA (\%), ascorbic acid $(\mathrm{mg} / 100 \mathrm{~g})$, fruit color (L, $\mathrm{a}, \mathrm{b})$, total chlorophyll $(\mathrm{mg} / 100 \mathrm{~g})$, the ratio of $\mathrm{O}_{2}$ and $\mathrm{CO}_{2}$ (\%) and $\mathrm{C}_{2} \mathrm{H}_{4}$ content (ppm) in MAP and overall appearance were observed in the peppers along the storage period at 10 day-intervals.

Weight losses occurred in fruits at each analytical period during storage were determined using Densi AC 100 precision balance ( $5 \mathrm{mg}$ precision) (Densi Industrial Balance Systems Co., Istanbul, Turkey), considering former weight value in each analytical period. TSS of pepper juice were determined using a NOW refractometer $(0-32 \%)$ (Tech-Jam International Inc., Tokyo, Japan) at $20{ }^{\circ} \mathrm{C}$ and results were reported as percentage. TA of pepper was titrated with $0.1 \mathrm{M}$ $\mathrm{NaOH}$ to $\mathrm{pH} 8.1$, and the results were expressed as percentage of citric acid. Ascorbic acid was determined by subjecting the samples taken from the fruits forming the replicate to extraction with oxalic acid $(0.4 \%)$ and then reading and calculating the absorbancy values at $520 \mathrm{~nm}$ in the spectrophotometer (Shimadzu UV-120-01) (Shimadzu Co., Duisburg, Germany) (Holden, 1976). The colors of fruits were measured using a Minolta CR-300 (Konica-Minolta, Osaka, Japan) colorimeter calibrated with a white standard tile. Total chlorophyll was determined by subjecting the samples taken from the fruits forming the replicate to extraction with acetone $(90 \%)$ and then reading and calculating the absorbancy values at $652 \mathrm{~nm}$ in the spectrophotometer (Holden, 1976). Dräger Multiwarn II gas analyzer (Drägerwerk AG, Lübeck, Germany) was used in determining the $\mathrm{O}_{2}, \mathrm{CO}_{2}$ and $\mathrm{C}_{2} \mathrm{H}_{4}$ concentrations under plastic film material forming the MAP. Overall appearance changes in the external appearances of normal atmosphere (NA) fruits, as well as MAP fruits, during storage were evaluated by a jury of 5 persons (as $1-2$ unusable, 3-4 unsalable, 5-6 salable, 7-8 good, 9-10 very good).

Statistical analysis The research was conducted using randomized plots factorial experimental design. The analyses were made in three replicates, being $500 \mathrm{~g}$ fruits in each replicate. Pepper cultivar and each analyses period used in the study were evaluated independently. Analysis of variance (ANOVA) was performed; means were compared by the least significant difference (LSD) tested at a significant level of 0.05 .

\section{Results and Discussion}

Weight loss Significant increases in weight loss took place during a prolonged storage period and the greatest losses occurred in NA treatment (Fig. 1A). Weight losses up to $20-25 \%$ were observed in peppers that could be stored in NA, whereas this rate was no higher than 3-5\% in MAP. Due to a low permeability, the packages have the high relative humidity. The type of packaging films significantly affected the maturity, where PP most effectively lowered maturity for peppers, thus extending the storage-life. Weight loss occurred due to moisture loss could have been leaded by the smaller vapor pressure gradient between fruits and environment in the direction of fruits. Moreover, MAP reduced the water loss by minimizing the contact of fruits with the surrounding air or by inhibiting the diffusion of water vapor with permeability of vapors of the films. Rona et al. (2003) also reported significant weight loss especially in untreated pepper fruit.

Total soluble solids The TSS values of the peppers generally exhibited nonsignificant increases throughout storage. In peppers, MAP slowed down the changes in TSS values, indicating the retardation of ripening due to the treatments. Moreover, the minimum increases in this parameter were recorded from PP and PVC treatments with 3.93\% and 4.13\%, respectively (Fig. 1B). TSS values were lower in PP and PVC in the fruits is an important result with respect to retarding the ripening in fruits. TSS contents of MAP peppers changed less, and in this way, TSS changes in plastic material treated fruits were suppressed, thus the ripening of fruits was inhibited. The TSS ratio which is generally related to 


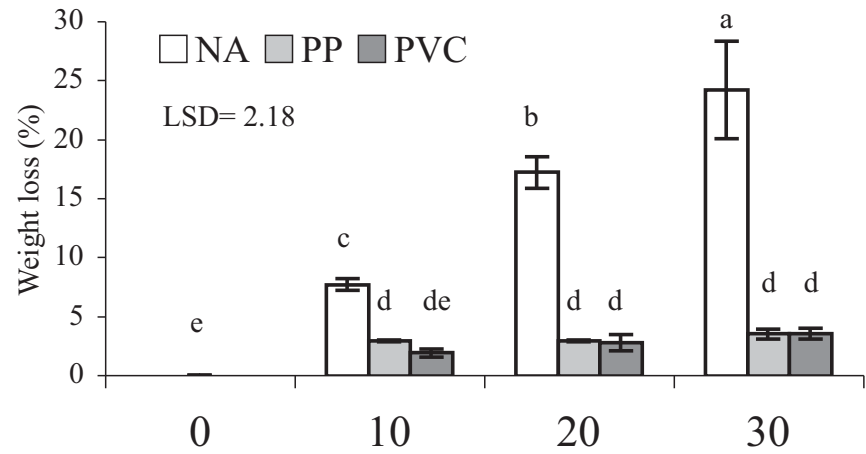

(A)

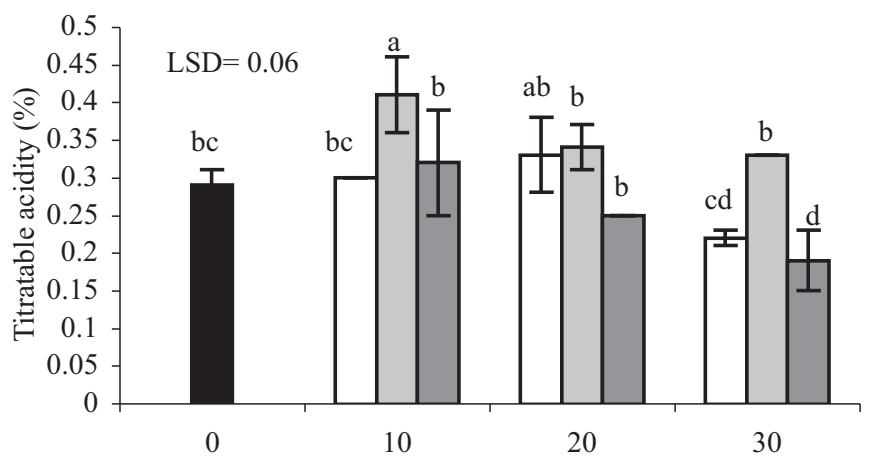

(C)

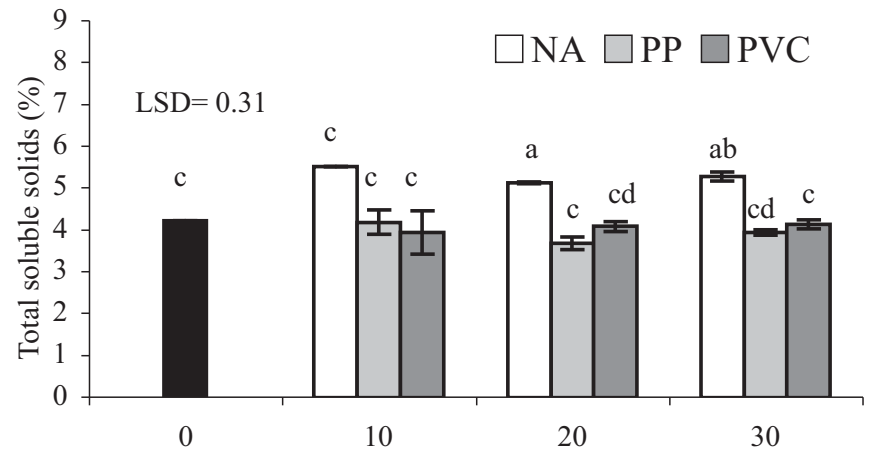

(B)

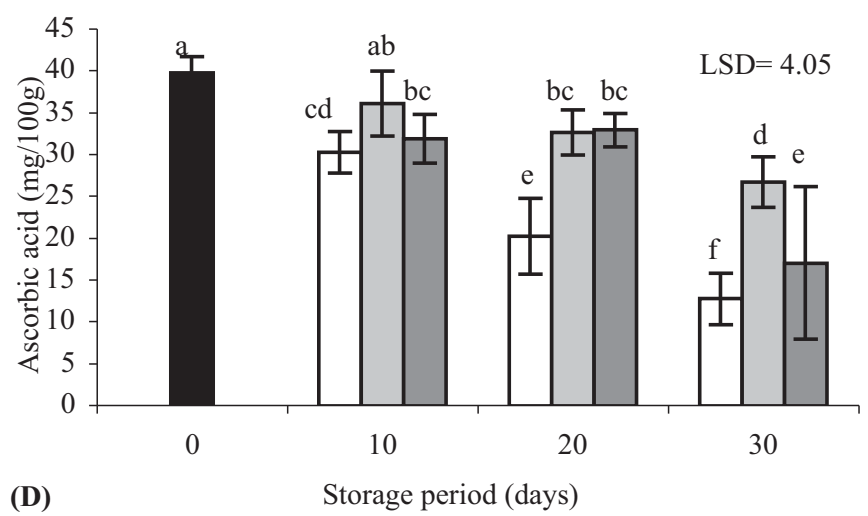

Fig. 1. Changes related to weight loss (A), total soluble solids (B), titratable acidity (C) and ascorbic acid (D) of pepper cv. 'Yalova Charleston' during NA and MAP $(\mathrm{P}<0.05)$.

sugar-acid metabolism and mineral content shows different changes depending on the storage temperature, atmosphere combination, and maturity stage of the fruit. Especially optimum low $\mathrm{O}_{2}$ and high rate of $\mathrm{CO}_{2}$ restricts this change under MAP conditions, which can be explained by more limited change of carbohydrate content resulting from the suppression of respiration metabolism. Gonzalez-Aguilar and Tiznado (1993), Ozden and Bayindirli (2002) examined the changes in TSS during the storage of pepper and determined that the TSS contents of peppers increased during storage. But, especially at the end of storage, decreases were also determined. The loss of soluble solids during the storage period is natural, as sugars, which are the primary constituent of the soluble solids content of a produce, are consumed by respiration and used for the metabolic activities of the peppers. Similar results were obtained in our study.

Titratable acidity It was determined that increases and reductions occurred in TA values of peppers during storage period. The lowest TA values were observed in NA and PVC fruits; whereas the highest TA values were obtained from PP application with which ripening proceeded more slowly (Fig. 1C). The PP plastic wrapper treatment caused TA contents of fruits to be higher than NA and PVC. Therefore, the loss of acidity in fruits was retarded through this treatment. These results are similar to those of a study conducted by Gonzalez-Aguilar and Tiznado (1993) and Martinez et al. (2003) on storage of pepper. The reduced TA in the fruit was the result of the acids being involved in physiological processes such as respiration. This is another important factor with regard to the treatments, especially in terms of slowing the loss of fruit quality. With these methods changes in fruit quality during storage could be kept within certain limits, since sugar accumulation was stable and loss of acidity was retarded in the fruit stored under the MAP.

Ascorbic acid Ascorbic acid contents of peppers show variations on treatments basis. In our study, reductions were observed in ascorbic acid values during storage. Also, in some other studies, there were statistically significant decreases in ascorbic acid over a 10 day storage period of unpacked and packaged peppers (Martinez et al., 2003, Gonzalez-Aguilar et al., 2004). However, the highest results with respect to ascorbic acid content in our study were obtained from PP treatment with 26.64 (Fig. 1D). High $\mathrm{CO}_{2}$ treatment retarded the change in ascorbic acid content as described above, but not in large amounts. Similar to the results obtained from our study, ascorbic acid loss was determined in the peppers stored at high temperatures under normal conditions; in a number of studies in which the ascorbic acid 

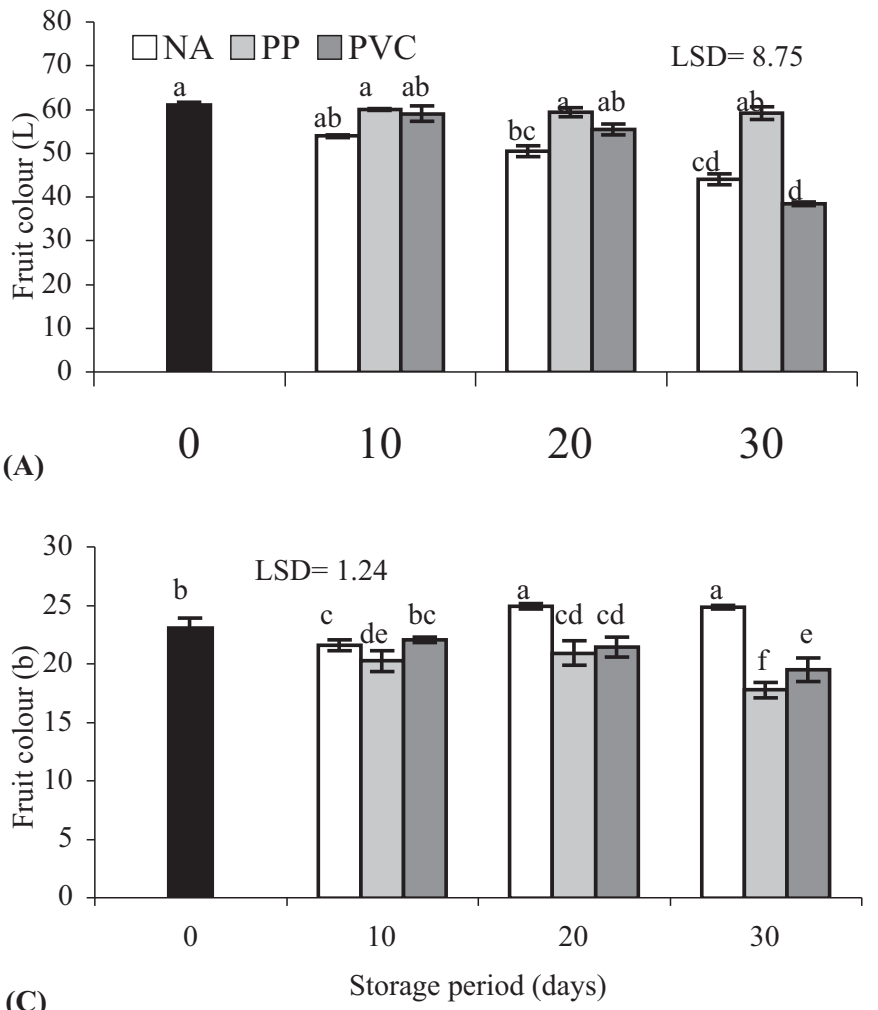

(C)

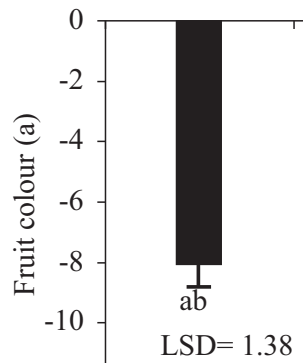

(B)
30
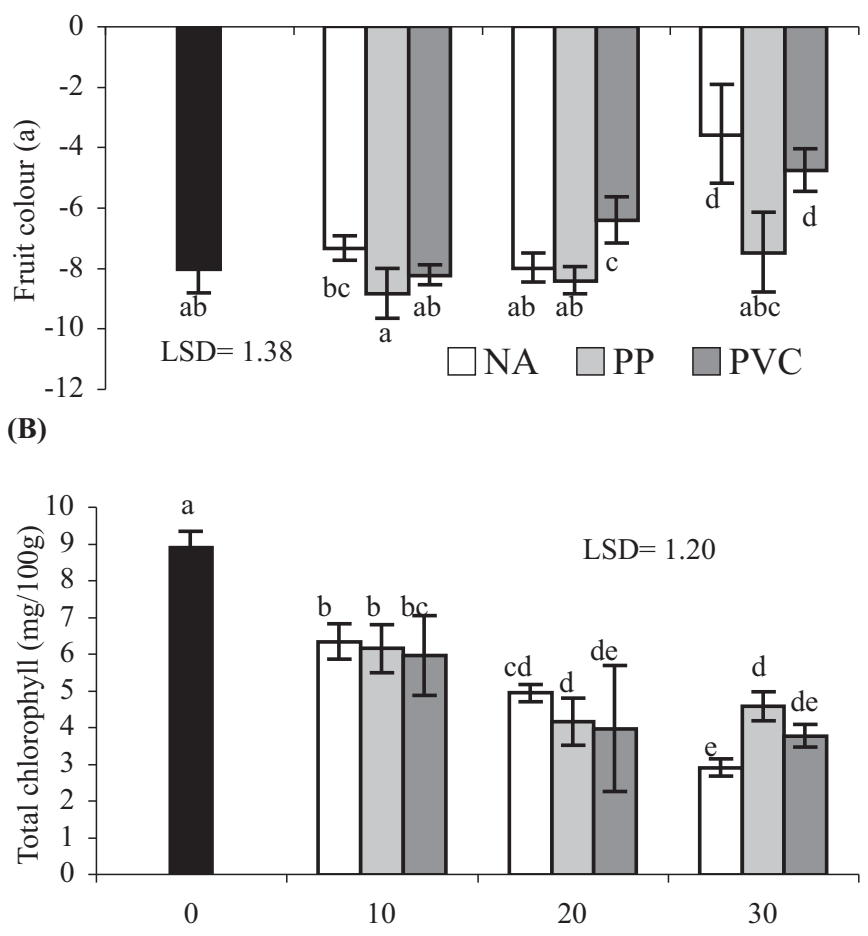

(D)

Storage period (days)

Fig. 2. Changes related to fruit color (L, a, b) (A, B, C) and total chlorophyll (D) of pepper cv. 'Yalova Charleston' during NA and MAP $(\mathrm{P}<0.05)$.

changes occurred during the storage of peppers were investigated (Jecheon et al., 2001).

Fruit color The fruit color was also examined in the study. Changes in fruit color at the end of storage proceeded more slowly in MAP. For example, the closest value to the initial color at the end of storage with MAP was observed with PP. The colors of fruits stored under NA conditions, changed rapidly and became dark. These results are in accordance with the findings of Martinez et al. (2003), Naik et al. (2001) and Meir et al. (1995).

There was a positive correlation between color values and chlorophyll values. Both values obtained from the fruits were observed to coincide with each other. Decreases occurred in the L values (brightness) of fruits in NA at the end of day 20th. L values decreases in MAP were found less than NA (Fig. 2A). It was observed that MAP treatments inhibited the decreases in the fruit brightness which was occurred by ripening. Therefore, a (green) values of the fruits subjected to NA and PVC treatments were found close to each other, as for the total chlorophyll values (Fig. 2B). The lowest total chlorophyll values were obtained from the NA. The b (yellow) values, which indicate the yellow color quantity, were notably higher in the fruits of PP treatment compared with the other treatments (Fig. 2C).

Total chlorophyll In general, reductions were observed in the total chlorophyll of peppers in NA and MAP. In the study, lower levels of chlorophyll quantity observed in NA was noted as a remarkable result (Fig. 2D). Chlorophyll is degraded by light as well as enzymes. Color changes occur in green peppers during ripening. Peppers that are green in color will have a chlorophyll content of $0.170 \mathrm{mg} / \mathrm{g}$, while yellow green peppers have less chlorophyll $(0.082 \mathrm{mg} / \mathrm{g})$ (Anonymous 1997). Ozden and Bayindirli (2002) investigated the effects of controlled atmosphere, cold storage and edible coating applications on shelf life and quality attributes of green peppers. In this study, chlorophyll, the primary pigment responsible for the green color of the peppers, decreased in all conditions during the storage period.

In-package atmosphere Fig. 3 (A, B and $\mathrm{C}$ ) shows the in-packaged atmosphere $\left(\mathrm{O}_{2}, \mathrm{CO}_{2}\right.$ and $\left.\mathrm{C}_{2} \mathrm{H}_{4}\right)$ changes during MAP. Reductions in $\mathrm{O}_{2}$ (Fig. 3A) and increases in $\mathrm{CO}_{2}$ and $\mathrm{C}_{2} \mathrm{H}_{4}$ (Fig. 3B) occurred following the transfer of peppers into MAP. Extreme reductions and increases in $\mathrm{O}_{2}, \mathrm{CO}_{2}$ and $\mathrm{C}_{2} \mathrm{H}_{4}$ ratios originating from the permeabilities of plastic film materials leaded to physiological disorders in fruits. High rates of $\mathrm{CO}_{2}$ accumulation and $\mathrm{C}_{2} \mathrm{H}_{4}$ formation was determined at the end of storage, especially with PVC treatment. This situation caused quality losses in fruits. These results are similar to those of a study conucted by Lee et al. (2006a) on MAP of fruit using plastic packaging materials. They re- 

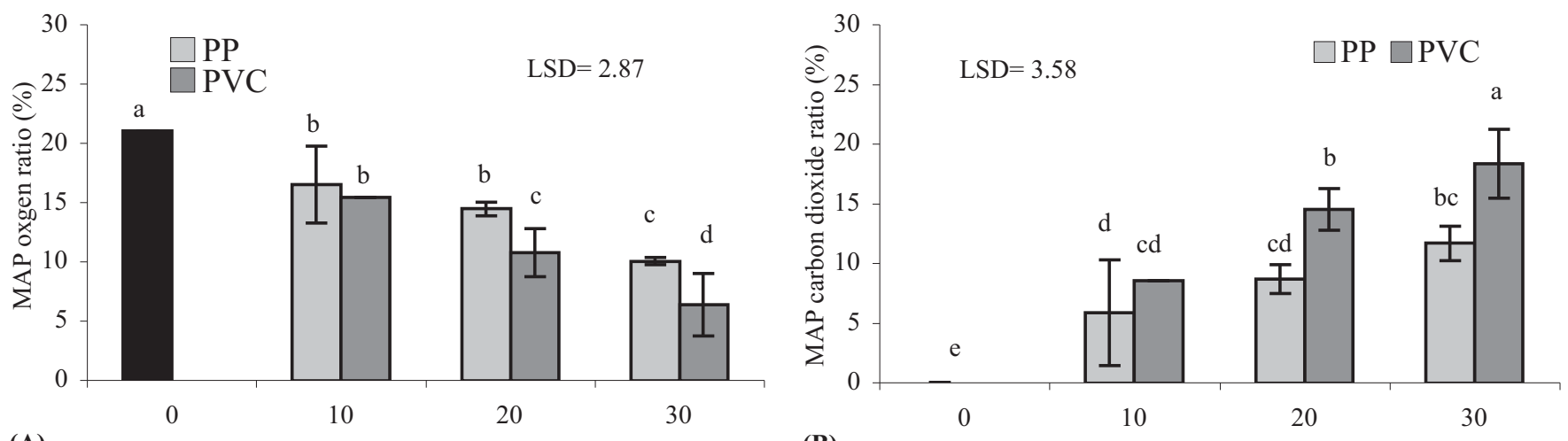

(A)

(B)
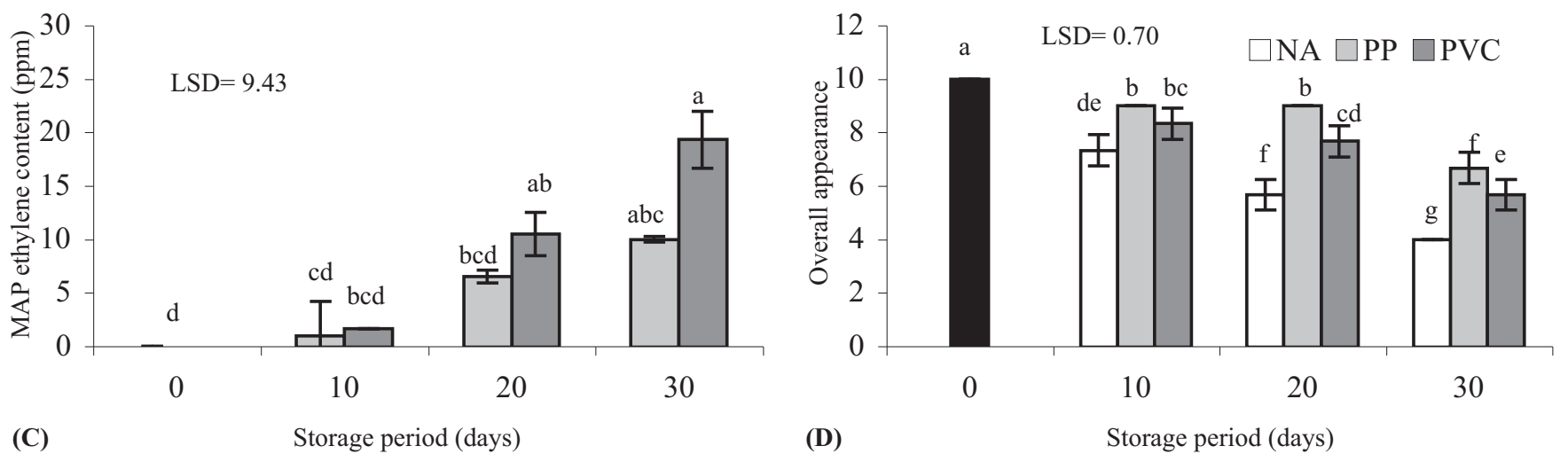

Fig. 3. Changes related to MAP oxygen (A) and carbon dioxide (B) ratio, MAP ethylene content (C) and overall appearance (D) of pepper cv. 'Yalova Charleston' during NA and MAP $(\mathrm{P}<0.05)$.

ported that pepper packages using $25 \mu \mathrm{m}$ low-density polyethylene and $30 \mu \mathrm{m}$ cast polypropylene could attain modified atmosphere close to the optimal gas concentrations $\left(3 \% \mathrm{O}_{2}\right.$ and $5 \% \mathrm{CO}_{2}$ ), and therefore provided better quality retention compared with unpackaged controls. Concentration of $\mathrm{O}_{2}$ in packs sealed with permeable films decreased and that of $\mathrm{CO}_{2}$ increased during the storage, after which a state of equilibrium was reached between respiration of the produce and the diffusion of these gases was counter balanced by production and consumption during respiration of the peppers and no further changes in the gas concentration within the packs occurred with fruit kept at constant temperature (Thompson 1998). In a different study, the respiration rates of fresh-cut bell peppers under diverse high and low $\mathrm{O}_{2}$ levels, with or without $20 \mathrm{kPa} \mathrm{CO}$, at 2,7 and $14^{\circ} \mathrm{C}$, were studied. In the study, a constant respiration rate of pepper dices throughout 3 days under different conditions was found. Fresh-cut peppers exposed to $0,0.5,1,3$ and $9 \mathrm{kPa} \mathrm{O}_{2}$ (all $\mathrm{CO}_{2}$-free), and to $0 \mathrm{kPa} \mathrm{O}_{2}+20 \mathrm{kPa} \mathrm{CO}_{2}$, had a lower respiration rate than peppers in the range $20-100 \mathrm{kPa} \mathrm{O}$ with or without $\mathrm{CO}_{2}$. Under high $\mathrm{O}_{2}, 20 \mathrm{kPa} \mathrm{CO}_{2}$ increased the respiration rate by about $20-40 \%$ compared to that in free- $\mathrm{CO}_{2}$ atmospheres, this effect being lower at low temperature. High $\mathrm{O}_{2}$ had little (at $14^{\circ} \mathrm{C}$ ) or no effect (at 2 and $7^{\circ} \mathrm{C}$ ) in stimulating both $\mathrm{CO}_{2}$ production and $\mathrm{O}_{2}$ consumption compared to normal air. High $\mathrm{CO}_{2}$ in the range $20-100 \mathrm{kPa} \mathrm{O}_{2}$ increased the respiratory activity of pepper dices, probably because physiological injury occurred at $14^{\circ} \mathrm{C}$. However, $20 \mathrm{kPa} \mathrm{CO}$ combined $^{2}$ with superatmospheric $\mathrm{O}_{2}$ neither induced a poor visual appearance nor off-odors. Consequently $50-80 \mathrm{kPa} \mathrm{O}$ combined with $20 \mathrm{kPa} \mathrm{CO}$ could be used in innovative modified atmosphere packaging of pepper dices to avoid fermentation and inhibit growth of spoilage microorganisms (Conesa $e t$ al., 2007). Moreover, elevated $\mathrm{CO}_{2}$ levels can reduce the products sensitivity to $\mathrm{C}_{2} \mathrm{H}_{4}$; it can also slow the loss of chlorophyll which is the green color of fruit and vegetables. High $\mathrm{CO}_{2}$ can also slow the growth of many of the postharvest fungi that cause rots. All these effects can help to extend the storage and shelf life of fresh produce (Jobling 2001, Lee $e t$ al., 2006a; Lee et al., 2006b; Conesa, 2007). Kang and Lee (1997) and Fallik et al. (1999) reported that respiration rate of green pepper increased during storage. In general, the reduction in $\mathrm{O}_{2}$ levels was accompanied with an increase in $\mathrm{CO}_{2}$. In another a study, respiration of green peppers at $10^{\circ} \mathrm{C}$ was characterized by the closed-system method as a function of $\mathrm{O}_{2}$ and $\mathrm{CO}_{2}$ concentrations, and was incorporated into mass balance equations of $\mathrm{O}_{2}$ and $\mathrm{CO}_{2}$ gases in order to predict the gas composition inside the package over time. From 
the prediction of atmospheres inside packages constructed of the available plastic films, retail packages were designed and studied experimentally for their ability to modify the package atmosphere and to retain quality (moisture, ascorbic acid and chlorophyll). Pepper packages using $25 \mu \mathrm{m}$ low-density polyethylene and $30 \mu \mathrm{m}$ cast polypropylene could attain modified atmosphere close to the optimal gas concentrations (3\% $\mathrm{O}_{2}$ and $5 \% \mathrm{CO}_{2}$ ), and therefore provided better quality retention compared with unpackaged controls (Lee et al., 2006a) .

The highest accumulation of $\mathrm{C}_{2} \mathrm{H}_{4}$ was observed in the product packaged in PVC (Fig. $3 \mathrm{C}$ ). $\mathrm{C}_{2} \mathrm{H}_{4}$ accumulation gradually increased during the storage, this fact was due to the permeability to gases observed commonly in MAP. Similar results have been observed using green pepper, where $\mathrm{C}_{2} \mathrm{H}_{4}$ increased to a maximum during the storage (GonzalezAguilar et al., 2004; Senesi et al., 2000). Rona et al. (2003) reported that $\mathrm{CO}_{2}$ and $\mathrm{C}_{2} \mathrm{H}_{4}$ contents were highest in nonperforated bags.

Overall appearance Different results were obtained on the basis of treatments as a result of overall appearance of peppers. NA fruits got lower scores compared with the other treatments. Moreover, variation was observed between all treatments at the end of storage. PP treatment got the highest scores at the end of storage period. Nevertheless, higher rates of deterioration in NA fruits caused to get low scores with respect to overall appearance (Fig. 3D).

When the overall appearance of fruits was considered, high rates of deterioration were observed in NA, in which high rates of weight loss was determined. The fact that these rates were especially high in NA may be stem from plastic covering treatments with these fruits. Thus, the result that the rates of overall appearance were better in MAP treated fruits, compared with NA fruits were considered as an important result with respect to the retention of quality of fruits during storage. These changes were supported by the results obtained from the studies carried out in different pepper cultivar by Ozden and Bayindirli (2002), Gonzalez-Aguilar et al. (2004) and Maalekuu et al. (2004). In addition to atmosphere modification, MAP vastly improves moisture retention, which can have a greater influence on preserving quality than $\mathrm{O}_{2}$ and $\mathrm{CO}_{2}$ levels. Furthermore, packaging isolates the pepper from the external environment and helps to ensure conditions that, if not sterile, at least reduce exposure to pathogens and contaminants (Mir and Beaudry, 2004).

\section{Conclusion}

When the overall appearance of fruits was considered, high rates of rotten fruit were observed in NA fruits, in which high rates of weight loss was determined. Moreover, decays and spoilages were intensively observed in these fruits as a result of rapidly proceeding physiological events and fungal effects. Especially, slower physiological processes in fruits subjected to MAP and lower incidence of spoilages in these fruits may be explained by the retention of fruit quality through MAP in terms of water loss. Moreover, the fact that these rates were especially high in NA fruits might stem from the high $\mathrm{O}_{2}$ and low $\mathrm{CO}_{2}$. These results suggest that the most important parameters to prolonging pepper storage period are storage temperature and atmosphere combinations. In this study, two film materials were used in order to see the effects of MAP treatments on the storage period and fruit quality of pepper cv. 'Yalova Charleston'. In the study, the spoilage and maturity was accelerated in NA treatment. Moreover, changes in the quality criteria of fruits could be kept within determined ranges by different atmosphere treatments. Disorders were reduced with low $\mathrm{O}_{2}$ and high $\mathrm{CO}_{2}$ during cold storage. However, higher quantities of $\mathrm{CO}_{2}$ and $\mathrm{C}_{2} \mathrm{H}_{4}$ associated with PVC cover material compared with PP cover material accelerated the quality losses in the peppers involved in this treatment. In conclusion, the fruits of pepper cv. 'Yalova Charleston' could successfully be stored for 30 days using $35 \mu \mathrm{PP}$ in the best quality and with slight changes in quality at $7{ }^{\circ} \mathrm{C}$ and $90 \pm 5 \%$ RH storage conditions.

Acknowledgement The author thanks to the Agromar Seed Company Ltd. for supplying seed.

\section{References}

Anonymous. (1997). D.3. "Chlorophyll”. http://scholar.lib.vt.edu/ theses/available/etd-041499-135944/unrestricted/etd4.pdf

Anonymous. (2003). “Agromar seed catalogue”. pp. 3-4.

Conesa, A., Verlinden, B.E., Artes-Hernandez, F., Nicolai, B. and Artes, F. (2007). Respiration rates of fresh-cut bell peppers under superatmospheric and low oxygen with or without high carbon dioxide. Postharvest Biol. and Technol. 45, 81-88.

Gonzalez-Aguilar, G.A. and Tiznado, M. (1993). Postharvest physiology of bell peppers stored in low density polyethylene bags. Lebens-Wissen und-Technol. 26, 450-455.

Gonzalez-Aguilar, G.A., Ruiz-Cruz, S. and Baez, R. (1998). Storage quality of bell peppers pretreated with hot water and polyethylene packaging. J. Food Qual. 22, 287-299.

Gonzalez-Aguilar, G.A., Ayala-Zavala, J.F., Ruiz-Cruz, S., AcedoFelix, E. and Diaz-Cinco, M.E. (2004). Effect of temperature and modified atmosphere packaging on overall quality of fresh-cut bell peppers. Lebens-Wissen und-Technol. 37, 817-826.

Fallik, E., Grinberg, S., Alkalai, S., Yekutieli, O., Wiseblum, A., Regev, R., Beres, H. and Bar-Lev, E. (1999). A unique rapid hot water treatment to improve storage quality of sweet pepper. Postharvest Biol . and Technol. 15, 25-32. 
Holden, A. (1976). "Chemistry and biochemistry of plant pigments". T.W. Goodwin (Ed.), Academic Press, London, pp. 1-37.

Hussein, A., Odumeru, J.A., Ayanbadejo, T., Faulkner, H., McNab, W.B., Hager, H. and Szijarto, L. (2000). Effects of processing and packaging on vitamin $\mathrm{C}$ and beta carotene content of ready-to-use (RTU) vegetables. Food Res. Int. 33, 131-136.

Jecheon, P., Sungmin, P., Keunchang, Y. and Cheonsoon, J. (2001). Changes in postharvest physiology and quality of hot pepper fruits by harvest maturity and storage temperature. Postharvest News and Info. 12, 1824.

Jobling, J. (2001). Modified atmosphere packaging: Not as simple as it seems. Good Fruit and Vegetables Magazine 11, 1-3.

Kang, J.S. and Lee, D.S. (1997). Susceptibility of minimally processed green pepper and cucumber to chilling injury by apparent respiration rate. Int. J. Food Sci. Technol. 32, 421-426.

Lee, K.S. Woo, K.L. and Lee, D.S. (2006a). Modified atmosphere packaging for green chili peppers. Packaging Technol. Sci. 7, 51-58.

Lee, L., Arul, J., Lencki, R. and Castaigne, F. (2006b). A review on modified atmosphere packaging and preservation of fresh fruits and vegetables: physiological basis and practical aspects-part I. Packaging Technol. Sci. 8, 315-331.

Maalekuu, K., Elkind, Y., Tuvia-Alkalai Shalom, Y. and Fallik, E. (2004). Quality evaluation of three sweet pepper cultivars after prolonged storage. Postharvest News and Info. 15, 1237.

Martinez, Y., Diaz, L. and Manzano, J. (2003). Influences of nitrogen and potassium fertilizer on the quality of "Jupiter" pepper (Capsicum annuum) under storage. Acta Hort. 628, 135-140.

Meir, S., Rosenberger, I., Aharon, Z., Grinberg, S. and Fallik, E. (1995). Improvement of the postharvest keeping quality and color development of bell pepper (cv. 'Major') by packaging with polyethylene bags at a reduce temperature. Postharvest Biol. and Technol. 5, 303-309.

Mir, N. and Beaudry, R.M. (2004). "Modified atmosphere packaging". http://www.ba.ars.usda.gov

Morales-Castro, J., Vazquez, C.M.A., Rocha-Fuentes, M., OchoaMartinez, A. and Gallegos-Infante, A. (2002). Effect of controlled atmospheres on quality of green pepper poblano (ancho). Proceedings of the $16^{\text {th }}$ International Pepper Conference, November 10-12, Tampico, Tamaulipas, Mexico.

Naik, J.P., Nagalakshmi, S., Balasubrahmanyam, N., Dhanaraj, S. and Shankaracharya, N.B. (2001). Packaging and storage studies on commercial varieties of Indian chillies (Capsicum annuum L.). J. Food Sci. and Technol. 38, 227-230.

Ozden, C. and Bayindirli, L. (2002). Effects of combinational use of controlled atmosphere, cold storage and edible coating applications on shelf life and quality attributes of green peppers. Eur. Food Res. Technol. 214, 320-326.

Qi, L., Wu, T. and Watada, A.E. (1999). Quality changes of freshcut honeydew melons during controlled atmosphere storage. $J$. Food Qual. 22, 513-521.

Rona, B., Jeonghee, C., Ilgın, M. and Daesung, J. (2003). Effects of perforated $\mathrm{PE}$ film packaging and storage temperature on quality of red pepper (Capsicum annuum). Postharvest News and Info. 14, 1961.

Senesi, E., Prinzivalli, C., Sala, M. and Genneri, M. (2000). Physicochemical and microbiological changes in fresh-cut green bell peppers as affected by packaging and storage. Italian J. Food Sci. 12, 55-64.

Thompson, A.K. (1998). "Controlled Atmosphere Storage of Fruits and Vegetables". CABI Publishing, Wallingford, Oxon, OX10 8DE, UK, pp. 278. 